\title{
Age related differences in phylogenetic diversity, prevalence of Shiga toxins, Intimin, Hemolysin genes and select serogroups of Escherichia. coli from pastured meat goats detected in a longitudinal cohort study
}

\author{
Eunice Ndegwa ${ }^{1 *}$ (D, Aber Alahmde², Chyer Kim', Paul Kaseloo ${ }^{2}$ and Dahlia O'Brien ${ }^{3}$
}

\begin{abstract}
Background: Little is known on significance, diversity and characteristics of gut $E$. coli in goats despite their importance as food animals globally. We characterized the temporal dynamics in diversity of $E$. coli in fecal samples from a cohort of goat kids and adult meat goats on pasture over a one-year period. Isolates were characterized based on phylogenetic grouping, virulence genes; shiga toxins 1 and 2 (Stx1\&Stx2) (STEC), intimin (eaeA), hemolysin (hly) and select important sero-groups (026, 045, 0103, 0126 and 0146) using molecular methods.

Results: A total of 516 E. coli isolates were screened. Prevalence of virulence genes and STEC was 65 and 56\% respectively. Prevalence of virulence genes and STEC was significantly higher in goat kids less than six months (76\% $166 \%)$ than adults (48\% /28\%). Isolates with virulence profiles of two or more genes were also higher in young goat kids (50\%) than adults (20\%). Entero-pathogenic E. coli (EPEC-eaeA gene only) were mostly from pre-weaned goat kids while hly gene only isolates were significantly higher in adults. The st $\times 1$, st $\times 2$ and hly genes peaked around weaning $(60,63$ and 52\%) respectively. Goats kids were mostly hosts to group D (59\%) while adults older than one year had B1 (75\%) isolates. Group D isolates were most abundant at weaning (64\%) and diarrhea samples (74\%). Group B2 isolates overall (6\%) were mostly detected around weaning (63\%) while A isolates were $4 \%$ overall. Twenty-four isolates belonged to sero-groups 026,0103 and 0146 with 70\% of the isolates detected around weaning. Nineteen of these isolates were STEC with most harboring the stx1/stx2/hly/eae (25\%) profile. Most belonged to O26 sero-group (75\%) and phylogroup D (75\%).

(Continued on next page)
\end{abstract}

* Correspondence: endegwa@vsu.edu

'Agricultural Research Station, Virginia State University, Petersburg, VA 23806,

USA

Full list of author information is available at the end of the article

(c) The Author(s). 2020 Open Access This article is licensed under a Creative Commons Attribution 4.0 International License, which permits use, sharing, adaptation, distribution and reproduction in any medium or format, as long as you give appropriate credit to the original author(s) and the source, provide a link to the Creative Commons licence, and indicate if changes were made. The images or other third party material in this article are included in the article's Creative Commons licence, unless indicated otherwise in a credit line to the material. If material is not included in the article's Creative Commons licence and your intended use is not permitted by statutory regulation or exceeds the permitted use, you will need to obtain permission directly from the copyright holder. To view a copy of this licence, visit http://creativecommons.org/licenses/by/4.0/. The Creative Commons Public Domain Dedication waiver (http://creativecommons.org/publicdomain/zero/1.0/) applies to the data made available in this article, unless otherwise stated in a credit line to the data. 


\begin{abstract}
(Continued from previous page)
Conclusion: To our knowledge this is the first study to highlight longitudinal age related differences in E. coli phylogenetic diversity, abundance of virulence genes and select important sero-groups in goats. Differences detected suggest a possible role of age and weaning stress in influencing $E$. coli diversity in the gut of goats. The findings are relevant to both animal and public health to advise on further studies on caprine $E$. coli isolates as animal and human pathogens.
\end{abstract}

Keywords: Goats, Age, Cohort, Virulence genes, Phylogenetic grouping, E. coli, Serotype

\section{Background}

Goats are an important source of meat and milk globally and are also gaining popularity in North America as a meat source due to an increased migrant demand [1]. However little is known about the diversity of $E$. coli in the gastrointestinal tract of goats including their potential as pathogens. E. coli is associated with a number of disease conditions in animals and humans. In ruminants, bacterial scours during pre-weaning and peri-weaning period are often caused by E.coli as primary pathogen or in complex interactions with parasites and viruses [2]. A key role of $E$. coli in neonatal diarrhea in goat kids was demonstrated by the reduced incidence of diarrhea in offspring when nursing does were vaccinated against $E$. coli during pregnancy [3]. E. coli pathotypes include enteric strains: enteropathogenic (EPEC), enterohemorrhagic (EHEC), enterotoxigenic (ETEC), enteroaggregative (EAEC), enteroinvasive (EIEC) and diffusely adherent (DAEC). Strains that cause extra-intestinal infections include those that cause urinary tract disease and meningitis and are generally referred to as ExPEC [4]. The ETEC strains are associated with diarrhea in young calves [5] while the EPEC strains whose characteristic hallmark is the attaching and effacing (A/E) lesion on the intestinal brush border are commonly detected in both healthy and diarrheic animal fecal samples [6]. They are also involved in causing diarrhea in young children. The ability to form the $\mathrm{A} / \mathrm{E}$ lesions is accorded by the intimin protein coded by the eaeA gene [7, 8]. Pathogenic E. coli utilizes a number of virulence factors to colonize and cause disease in animals and humans among which, shiga toxins 1 and 2 (Stx1, Stx2), intimin (enterocyte attaching and effacing protein (eaeA) and hemolysin are well known and widely studied [9]. The shiga toxin producing E. coli (STEC) produce either shiga toxin 1, shiga toxin 2 or both and the genes are carried by bacteriophages [10]. Additionally they produce other virulence molecules that determine their pathogenicity in different host tissues [9]. The role of STEC in causing diseases in ruminants, the predominant host reservoirs [8] and also other farm animals is not clearly understood. They have been isolated in feces from both healthy and diarrheic animals $[8,11]$. On the other hand, STEC strains are important human pathogens and includes strains that cause bloody diarrhea, non- bloody diarrhea and urinary tract infections in humans (EHEC) [8]. The most studied of this pathotype is the O157:H7 serotype although the importance of other non-157 STEC in human disease is now widely acknowledged [12-14]. Both shiga toxin 1 and 2 inhibit cell protein synthesis by cleaving the ribosomal RNA resulting in cell death $[4,10]$. While the shiga toxin 1 is highly conserved in shiga toxin -producing E.coli (STEC), the shiga toxin 2 is highly variable with some variants being more associated with higher virulence in humans [15]. The importance role of nonO157 E.coli STEC strains in public health has recently been reviewed [16-18]. Ruminants including cattle, sheep and goats are known to be reservoirs to E. coli isolates of public health importance including STEC O157 and non-O157 strains [7]. Some non-O157 STEC serotypes $(026,045)$ from goats have also been associated with diarrhea in people $[17,19]$. Acknowledging the importance of STEC in public health, Europe now requires and emphasizes meat inspection efforts to ensure absence of STEC from slaughtered small ruminants [20]. Only a few studies have characterized prevalence of virulence genes in E.coli isolates from goats and sheep [21-26]. Moreover, prevalence of these important E. coli strains (STEC, EPEC) and their virulence gene profiles have not been investigated in US sheep and goat flocks despite the increasing number of meat goats in the US for the last decade and existence of several dairy goat flocks and also sheep flocks. Additionally, sheep and goats are almost always part of livestock found in petting zoos, state fairs and also companion animals in some US homes. Thus these animals interact with people closely and also with the environment as most are reared in pastures. Goats have been incriminated in human non O157 E.coli outbreaks (O45) through contact [17] and recent study in meat goats in a US slaughter house detected a number E.coli serotypes in fecal samples that are of significance to public health underscoring the need for more studies targeting meat goats [27].

In studies from other countries in Europe the findings on the prevalence of important E.coli virulence genes differ from study to study [21,24], different geographical 
locations, different ages, different seasons [28] and species of animals. In cattle and dairy goats, the pattern of expression of the different virulence genes by $E$. coli has been shown to differ based on age of the host. Stress has also been shown to cause increased prevalence of certain virulent strains including $\mathrm{O} 157$ in cattle $[29,30]$. Thus it seems that colonization and shedding of important E.coli strains in a host may be dependent on many factors that have yet to be fully described including age, geographic location, stress, management factors, and production system among others [31].

E.coli are generally characterized into four phylogenetic groups that include A, B1, B2 and D based on the presence of the chuA and yjaA, and the anonymous DNA fragment Tspe4.C2 [32, 33]. Studies have shown that the phylogenetic groups differ in the ecological niches they predominantly inhabit, size of genomes, presence of virulence factors and in some cases the presence of antibiotic genes. In particular, the virulent extra-intestinal serotypes are mostly found in group B2 and often in group D whereas, majority of the commensal serotypes fall in group A and B1. Intestinal pathogenic strains are mainly the phylogenetic groups A, B1 and D (reviewed in [34]).

With limited information on the diversity of gut commensal E. coli in meat goats and their significance as pathogens, this study was designed with the objective of characterizing the temporal dynamics in E. coli phylogenetic distribution, prevalence of select virulence genes and select important serotypes in pastured meat goats of different age groups.

\section{Results}

Prevalence of virulence genes in pre-weaned goat kids and nursing does

All goat kids and nursing does were apparently healthy at the time of sampling and grazing together on pasture. In total, $128 \mathrm{E}$. coli isolates that included 75 and 53 isolates from goat kids and does respectively were screened for virulence genes over the three sampling points before weaning. The virulence genes stx 1 , hly, and eaeA were detected in goat kids as young as 3 weeks old and were detected at each of the three sampling points. In nursing does, only the virulence genes stx 1 and/or hly were detected at all the three sampling points. The $s t \times 2$ gene was detected in very few isolates from goat kids during the same period but none of the isolates harbored the enterohemorrhagic Escherichia coli (EHEC) type Stx 2 gene. In young goat kids the prevalence of stx 1 ranged from 30 to 58\%, stx 2; 4-29\% eaeA; $7-71 \%$ and hly 22-63\%. In nursing does the prevalence of the genes stx 1 ranged from 10 to $21 \%$, stx 2 variant $0-20 \%$, eaeA $0-5 \%$ and hly $14-29 \%$. For both stx 1 and $e a e A$ genes, the prevalence in $E$. coli isolates from pre- weaned goat kids was significantly higher $(P=0.0002$ and $P<0.0001)$ respectively than those from the nursing does (Fig. 1). It was interesting to note that a high percentage of $E$. coli isolates from apparently healthy 3week goat kids harbored the eaeA gene (71\%). The mean prevalence of the virulence genes in the two groups during the three sampling points is shown below (Table 1).

\section{Prevalence of virulence genes during weaning period}

The weaning period is a stressful period in young animals and is often associated with diarrhea in most farm animals. It is unclear if any of the $E$. coli virulence genes evaluated in the study plays a role in colonization of $E$. coli in the gut of ruminants including goats. To evaluate if weaning stress affects the prevalence virulence genes in $E$. coli isolates from young goat kids around the weaning period, we screened $163 \mathrm{E}$. coli isolated from the goat kids during the weaning period (day of weaning (ODPW), one day after weaning(1DPW), two days after weaning (2DPW) and seven days after weaning (7DPW). The four virulence genes were detected in all days sampled during the peri-weaning period (Fig. 2 and Table 1). The three genes $s t x 1, s t x 2$ variant, and $h l y$ were detected in a high number of $E$. coli isolates at $1 \mathrm{DPW}, 2 \mathrm{DPW}$ and 7DPW. The Stx 1 gene prevalence in these isolates ranged from 65 to $74 \%$ while $H l y$ ranged from 58 to $70 \%$ during the three days post weaning. A unique pattern in which the prevalence of both stx 1 and hly genes increased significantly from ODPW to the other sampling days (1DPW $P=0.001)$, (2DPW $P=0.0007)$ and (7DPW $P=0.009)$ for Stx 1 and hly (1DPW $P=0.0001)$, (2DPW $P<0.0001)$, (7DPW $\mathrm{P}<0.0001)$ was also noted. The highest prevalence of Stx 1 and hly genes were detected in $E$. coli isolate at 1DPW (74\%) and 7DPW (67\%) of isolates respectively. Even at one-week post weaning the prevalence of these two genes was still higher than at the day of weaning (ODPW). Another key finding was the detection of the $E$. coli isolates harboring the stx 2 (EHEC) type gene during this period for the first time in the study. Although detected in a few number of isolates (11-20\%), the gene was detected each day during the four sampling points around weaning. The other stx 2 variant gene was also detected in a high number of isolates during the same weaning period ranging from 54 to $71 \%$ of the isolates. The highest prevalence was detected on the first day after weaning (71\%) but the gene was still detected in over $50 \%$ of the isolates at 2DPW and one week after weaning.

\section{Prevalence of virulence genes in post weaned goats and adults}

In total, $66 \mathrm{E}$. coli isolates were screened for the virulence genes in the six-month old goats and 42 isolates at one year of age. The stx 1 and $h l y$ genes were detected in 


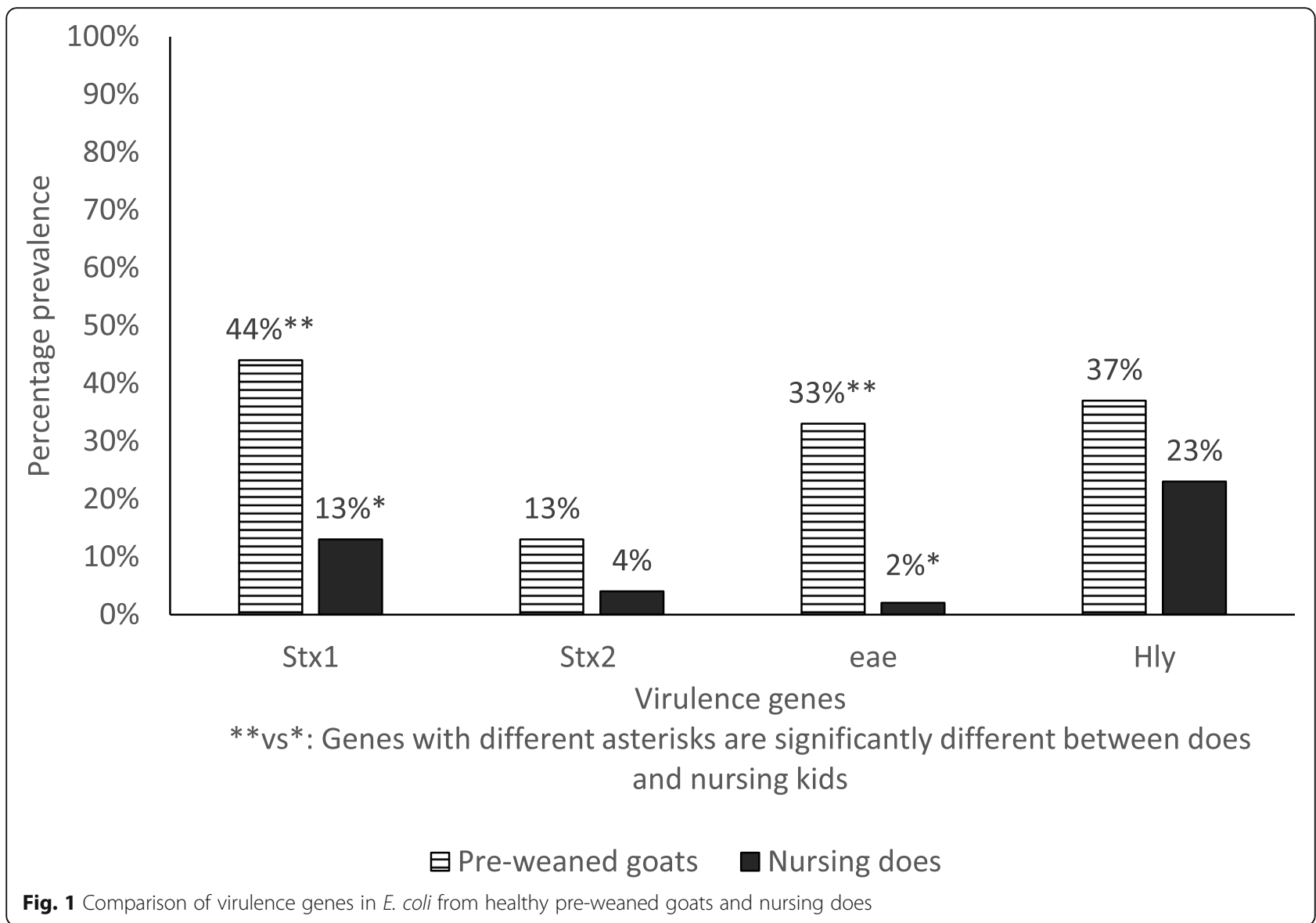

$45 \%$ vs 31 and $44 \%$ vs $31 \%$ of the isolates from six and one year of age respectively. The eaeA gene was detected in $2 \%$ of the isolates from six months old goat kids while none was detected in isolates from one-year-old goat kids. The stx2 variant gene was detected in 18 and $31 \%$ of the isolates from six months and one of year age respectively. In adults grazing alongside the cohort of the young growing goats, st $x 1$ and $h l y$ were detected in 26 and $32 \%$ of the $102 \mathrm{E}$. coli isolates. Stx 2 gene was detected in $7 \%$ while eaeA were detected in less than $5 \%$ of the adult isolates (Table 1).

\section{Virulence gene profiles of $E$. coli isolates from different age groups}

Of the isolates positive for the virulence genes, the genes were either detected singly or in fourteen different combinations. In general, the prevalence of virulence genes and STEC in kids less than six months was significantly higher than adult goats older than one-year $P<0.0001$. The highest diversity of isolates based on the virulence gene combinations detected was also in goat kids during peri-weaning [15] and pre-weaning [14] weaning period (Additional file 1) with isolates harboring 2 or more

Table 1 E. coli virulence genes screened and number of positives isolates in different pastured goat age groups

\begin{tabular}{llllllll}
\hline & Pre-weaned kids & Nursing does & Weaning period (kids) & Six months & Yearling & All adults & Diarrhea \\
\hline Virulence genes & $n=75$ & $n=53$ & $n=163^{b}$ & $n=66$ & $n=41$ & $n=102^{\mathrm{a}}$ & $n=47$ \\
Stx1 & $30(40)$ & $7(13)$ & $99(61)$ & $30(45)$ & $13(31)$ & $27(26)$ & $23(49)$ \\
Stx2 (EHEC type) & 0 & 0 & $24(15)$ & 0 & 0 & 0 & $8(17)$ \\
Stx2 (other) & $10(13)$ & $2(4)$ & $101(62)$ & $12(18)$ & $13(31)$ & $7(7)$ & $26(55)$ \\
EaeA & $25(33)$ & 0 & $29(22)$ & 0 & 0 & $2(2)$ & $3(6)$ \\
Hly & $28(37)$ & $12(23)$ & $74(45)$ & $29(44)$ & $13(31)$ & $33(32)$ & $17(36)$ \\
\hline
\end{tabular}

aincludes the nursing does isolates; () values in brackets represent percentages. ${ }^{b}$ value in () in this column represent the mean prevalence of the four sampling days 


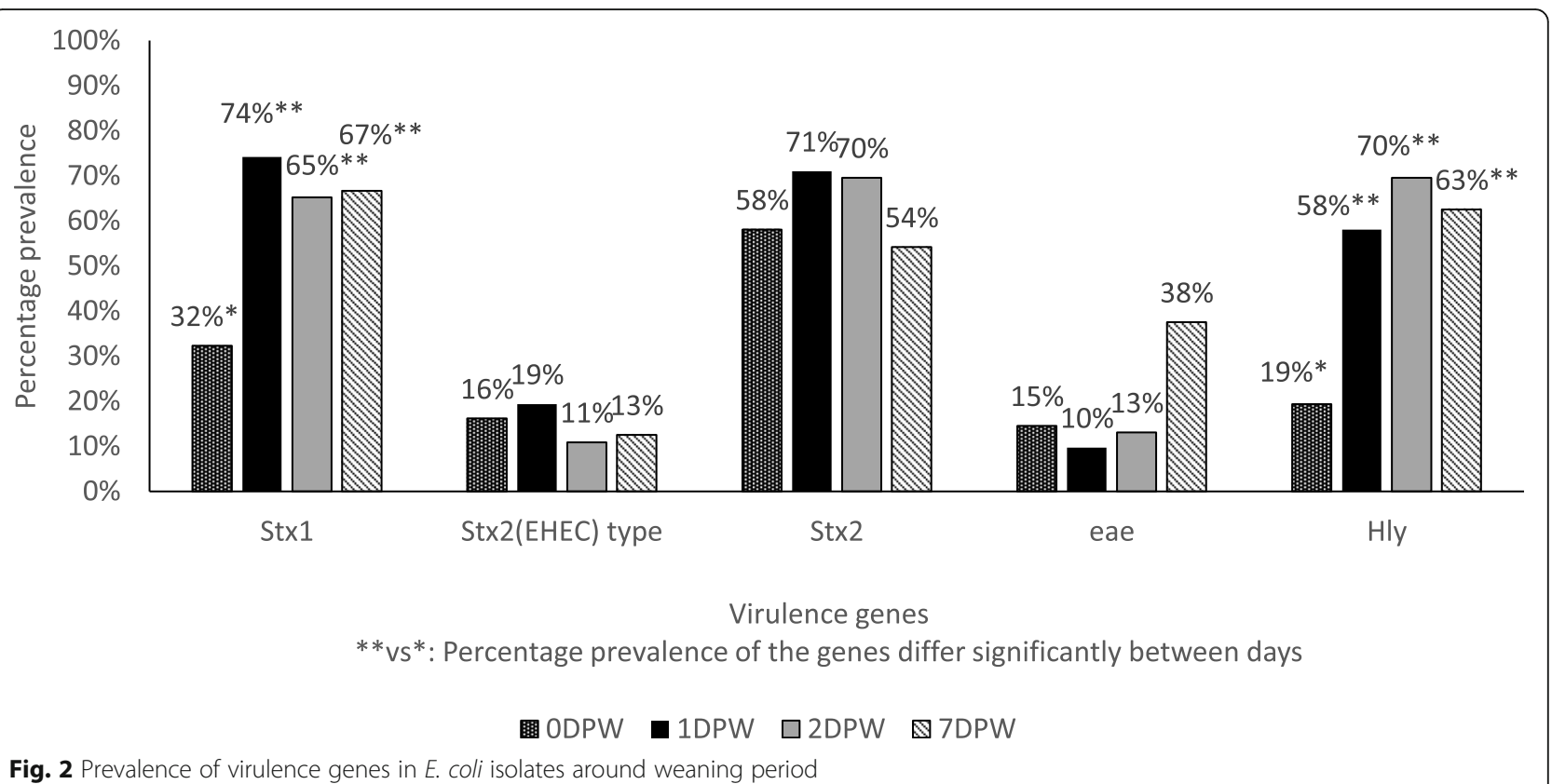

virulence genes being significantly higher $(\mathrm{P}<0.0001)$ than in adult goats. The highest proportion of isolates in the cohort harbored stx $1 /$ stx $2 / h l y$ (20\%), followed by stx1/hly (19\%), stx2 (15\%), stx1(10\%), hly (9\%), stx1/stx2 (7\%), eaeA (4\%), stx1/stx $2 / h l y / e a e A ~(4 \%), ~ s t x 2 / h l y ~(3 \%)$ and stx1/eaeA/hly (3\%). The prevalent gene combinations in isolates differed among age groups. In nursing goat kids, most positive isolates harbored a combination of stx1/hly (27\%) followed by eaeA alone (24\%) while other virulence gene combinations were detected in less than $10 \%$ of the positive isolates. A significantly higher proportion of isolates from adult nursing does and other adults on the farm harbored only the hly genes (39\%) $(P<0.0001)$ compared to goat kids less than six months while $24 \%$ harbored stx $1 / h l y$ genes. Stx 1 and $s t x 1 / s t x 2$ isolates were detected equally in the nursing does group (Additional file 1). Most isolates at around weaning harbored the stx $1 /$ stx $2 / h l y$ (29\%) virulence gene combinations followed by stx $2(22 \%)$ alone and stx $1 / s t x 2$ and stx $1 / s t \times 2 / h l y / e a e A$ both of which were detected in $8 \%$ of isolates each. Isolates from 6 months and yearling goats were mostly of the stx1/hly profile (39\%) and (42\%) respectively but a significant numbers of isolates from yearling goats also harbored $s t x 2$ (42\%) (Additional file 1).

\section{Pattern of virulence genes among age groups}

All the isolates from the different age groups of goats were grouped together and the prevalence of the virulence genes in $E$. coli isolates calculated; isolates from pre-weaned goat kids, peri-weaning, six months, yearling and adult animals (pre-weaning and six months later) (Table 1 and Fig. 3. Comparing the different age groups, the highest prevalence and the most diverse virulence genes were detected during the weaning period and the lowest prevalence and diversity was detected in the isolates from goats older than one year. While hly and stx 1 were detected in all age groups all the five different genes (stx1, stx2 (EHEC), Stx2 variants, eaeA and $h l y$ ) evaluated were only detected during the weaning period (Fig. 3).

\section{Phylogenetic diversity of $E$. coli isolates from the meat goats}

Five hundred and sixteen (516) E. coli isolates from the different age groups were genetically characterized using the chuA, yjaA and DNA fragment TspE4.C2 as described in materials and methods. The four known phylogenetic groups were detected in all age groups. The predominant E. coli phylogenetic groups detected in the cohort were D 239 (46\%) and B1 230 (45\%) while group B2 [32] and group A [18] were each 6 and 4\% respectively (Table 2). In particular, comparing the cohort of pre-weaned nursing goat kids and their respective does who were grazing alongside each other, we found that the predominant phylogenetic groups differed. $E$. coli isolates from goat kids belonged to mostly group D phylogenetic group (49\%) and B1 (43\%) while those from the nursing does belonged to predominantly group B1 (62\%). Twenty-eight (28\%) of isolates from the nursing does belonged to group D. Likewise, as a group, E. coli isolates from goat kids around weaning belonged mostly to group D phylogenetic group (64\%) followed by group B1(21\%). There was a significant increase $(P=0.02)$ in 


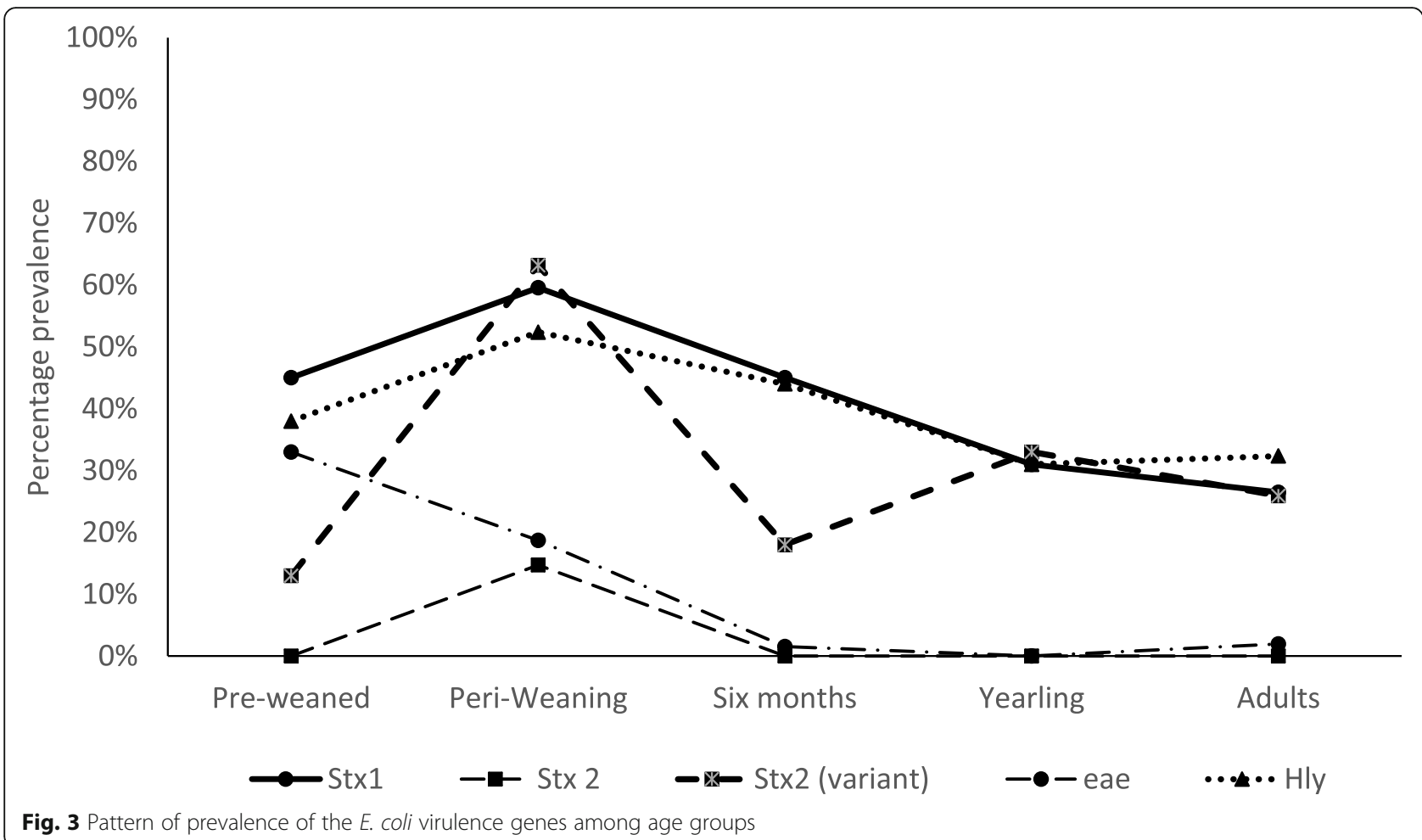

the proportion of group D isolates during the weaning period compared to the pre-weaning period. In the sixmonth cohort of goats, isolates belonged to group B1 (51\%) and group D (46\%) while isolates from one-yearold goats belonged to group B1 (56\%) and group D (38\%) (Fig. 4). On the other hand, E. coli isolates from adults older than one year belonged to B1 (75\%) and group D (15\%). An interesting pattern was noted in the prevalence of group D and group B1 phylogenetic groups among the different age groups evaluated (Fig. 4) where group $\mathrm{D}$ isolates decreased as the animals grew older while on the other hand group B1 isolates increased with age. Of note was the significantly higher proportions of isolates belonging to group $\mathrm{D}$ in preweaned goat kids compared to adult animals $(P<0.0001)$ while on the other hand the proportion of group B1 isolates was significantly higher in adult animals $(\mathrm{P}<$ 0.0001) than pre-weaned goat kids. Thirty-two [32] isolates belonged to the B2 phylogenetic group. Of these, [25] were isolated from goat kids less than six months while (1, 2 and 4 isolates) were isolated from six months, yearling and adult goats respectively. Group A isolates were less than $10 \%$ in all age groups. The highest prevalence of isolates belonging to groups $\mathrm{D}$ and $\mathrm{B} 2$ in

Table 2 Phylogenetic groups of E. coli isolates from different age groups of meat goats and detection of select important serotypes

\begin{tabular}{|c|c|c|c|c|c|c|c|c|}
\hline Age group & Pre-weaned kids & Peri-wean & 6 months & Yearling & Does (pre-wean) & Other adults & Diarrhea & Total \\
\hline Phylo-group & $n=75$ & $n=159$ & $n=66$ & $n=40$ & $n=53$ & $n=72$ & $n=47$ & $n=516$ \\
\hline A & 1 & 4 & 2 & 2 & 4 & 4 & 1 & $18(4)$ \\
\hline B1 & 32 & 34 & 33 & 22 & 36 & 62 & 11 & $230(45)$ \\
\hline B2 & 5 & 20 & 1 & 2 & 1 & 2 & - & $31(6)$ \\
\hline D & 37 & 102 & 30 & 15 & 12 & 4 & 35 & $239(46)$ \\
\hline \multicolumn{9}{|l|}{ Serotype } \\
\hline $\mathrm{O} 26$ & 2 & 14 & - & - & - & - & 2 & 18 \\
\hline $\mathrm{O} 45$ & - & - & - & - & - & - & - & - \\
\hline 0103 & 1 & 3 & - & - & - & - & - & 4 \\
\hline 0126 & - & - & - & - & - & - & - & - \\
\hline 0146 & _ & 2 & _ & - & _ & _- & _ & 2 \\
\hline
\end{tabular}




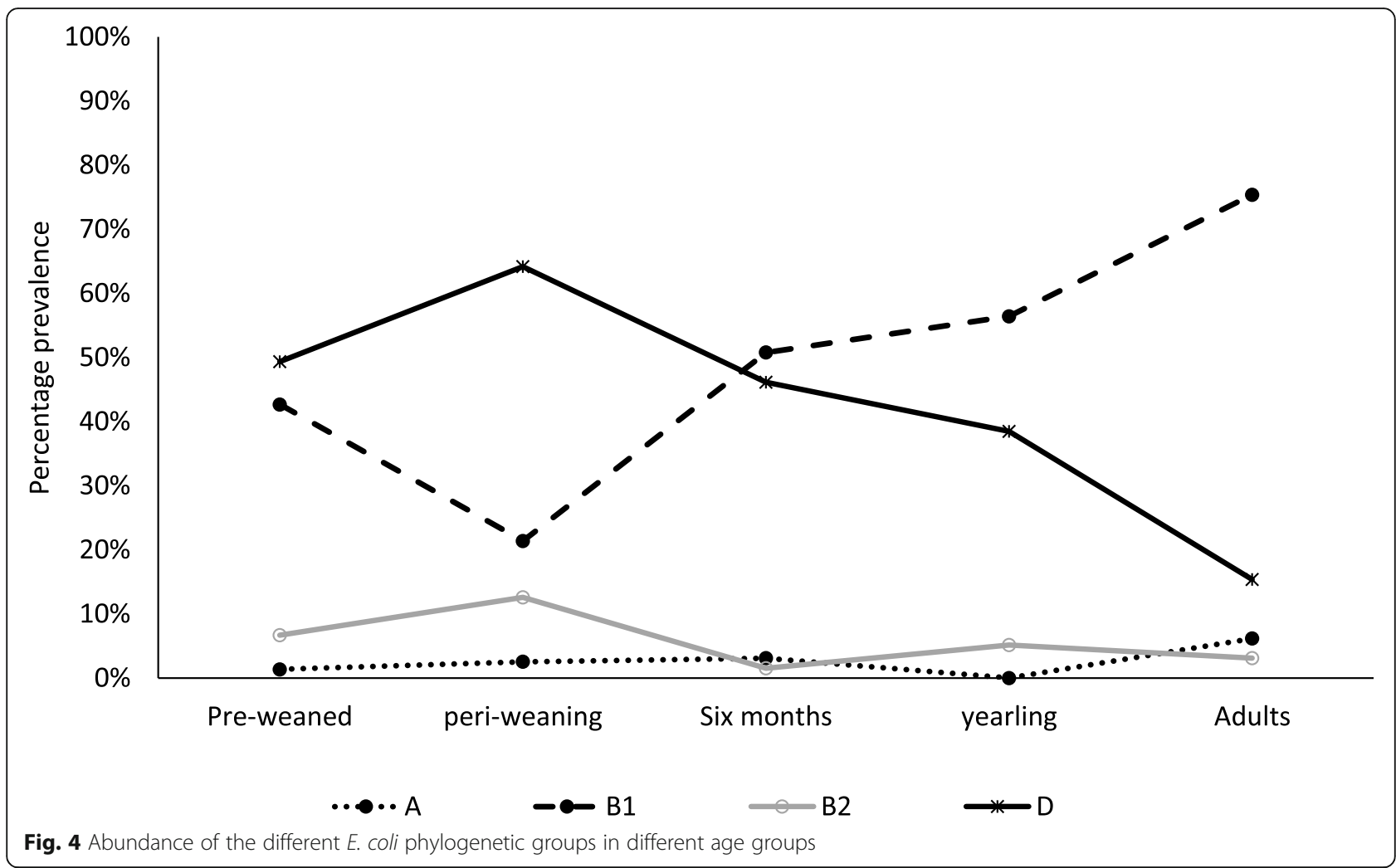

apparently healthy goats were detected during the periweaning period (64 and 13\%) respectively (Fig. 4 and Table 2). Of the isolates that were also screened for virulence genes, the association between the detected gene combinations and the phylogenetic groups is shown in Additional file 1: Table 1. Overall, most isolates positive for at least one virulence genes belonged to group $D$ (55\%), followed by group B1(34\%), while group A and B2 were 6 and 5\% respectively. Except isolates harboring single genes (stx $1, s t x 2$ or $h l y)$ which belonged to group $\mathrm{D}$ and $\mathrm{B} 1$ in equal numbers, all other isolates containing two or more virulence genes belonged to group D. Of exception was those isolates with eaeA only which predominantly belonged to group $\mathrm{D}$. Isolates belonging to group B2 were distributed in equal numbers in all gene combinations while group A isolates were mostly those that did not harbor the eaeA gene (Additional file 1).

\section{Detection of select important $E$. coli sero-groups}

Among the sero-groups evaluated (026, 045, 0103, 0126, and 0146), only three sero-groups were detected in this study and included 026, 0103 and 0146 (Table 2). In total 24 isolates belonged to these three sero-groups with the most common being 026 [18] while [4] belonged to 0103 and the other [2] belonged to the 0146 sero-group. Interestingly, all the isolates were detected in young goat kids less than six months and especially around the weaning period. Of the 24, twenty-two [21] were detected around the weaning period (0-7DPW). Two [2] of the 026 isolates were detected in the diarrhea group while the rest were detected in apparently healthy goat kids. All except one of the isolates harbored at least one virulence gene and the virulence gene profiles and the phylogenetic groups for the other isolates are shown in Additional file 2. Most of the isolates were stx1/stx2/ hly/eaeA positive (23\%) while $12 \%$ had only the hly gene detected. The other combination of genes was detected in less than $10 \%$ of the isolates. Of these isolates, $75 \%$ belonged to the D phylogroup, $21 \%$ to $\mathrm{B} 2$ and $4 \%$ to $\mathrm{B} 1$.

\section{Prevalence of virulence genes and phylogenetic grouping of $E$. coli isolates from diarrheic samples}

A total of 47 samples were isolated from diarrheic stools from young goats during the study. The stools were either collected from kids before weaning (17 isolates) or at day of weaning ODPW (4 isolates), 1DPW [12] or 2DPW [14]. Most diarrheic stools were detected during the weaning period. The prevalence of the virulence genes in this cohort was stx 1 (49\%), stx2 variant (57\%), stx2 (17\%), hly (36\%) and eaeA (4\%) (Fig. 5). The most significance finding in this group was the relatively higher prevalence of both the EHEC type stx2 genes and the other Stx 2 genes which mirrored the prevalence detected in the healthy peri-weaning group (15 and 54\% 


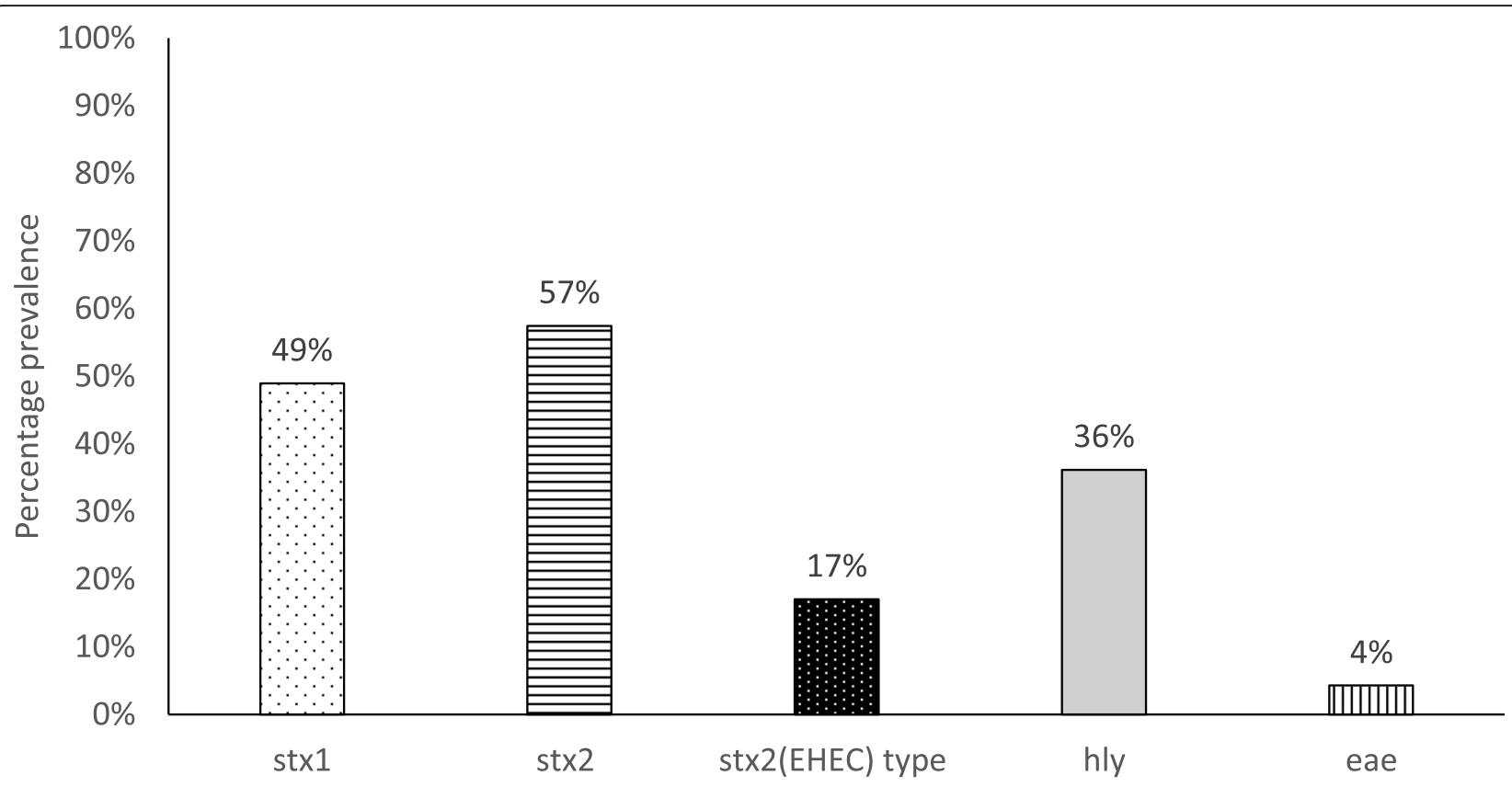

Fig. 5 Prevalence of virulence genes in $E$. coli isolates from diarrheic animals

respectively). Nine different virulence profiles were detected in the positive isolates from this group. Similar to the peri-weaning group, most isolates were of the stx $1 /$ st $x 2 / h l y$ virulence profile (35\%), st $x 1 / s t \times 2$ isolates were $16 \%$, while stx 1 and stx 2 isolates were each $13 \%$ (Additional file 1). Isolates from diarrheic goats belonged to three phylogenetic groups; A, B1 and D (Table 2). Overall, group D was the most common $(74 \%)$ in isolates that were positive for virulence genes irrespective of virulence profiles followed by group B1 23\% (Additional file 1$)$. We detected a significantly $(P=0.05)$ higher percentage of D phylogenetic group (74\%) E. coli isolates in the diarrhea group compared to the other age matched healthy littermates six months and below (59\%).

\section{Discussion}

Escherichia coli is a normal inhabitant of the mammalian gut but some strains have the ability to cause enteric and extra-intestinal diseases in both animals and human. Few studies have evaluated or reported the diversity and virulence characteristics of $E$. coli isolates in goats. Moreover only one study that involved longitudinal characterization of E.coli isolates in goats was found in literature [25].

In this study, all the four virulence genes (stx1, stx 2 (EHEC), stx2, eaeA and $h l y$ ) evaluated were detected in at least one isolate either singly or in combination. Overall, virulence genes and STEC were detected in isolates from goat kids in higher proportions than adult animals. Additionally, isolates with 2 or more virulence genes were significantly higher in pre-weaned and goat kids around weaning than in adult goats. Most isolates harbored either the $s t x 1 / s t x 2 / h l y$ or $s t x 1 / h l y$ virulence profile. This is similar to findings reported in dairy goats in Spain [21]. Isolates with a single gene $(h l y)$ were more frequently detected in isolates from adult goats than young goat kids. We also found that isolates harboring Stx 1 and Hly were present in all age groups beginning as early as three weeks of age but the prevalence varied in different age groups. These results may imply that $E$. coli harboring these genes are adapted to colonizing the gastrointestinal gut of healthy meat goats and may persist in the animal gut once established. This is in agreement with previous studies, in dairy goats in Spain where they found STEC in goat kids as early as the first week of life [25] as well as other age groups including adult goats [25, 31]. Another study also found E.coli harboring virulence genes in goat milk and goat environment [35] and in Germany 75\% of adult goats were found to harbor Stx1 positive E.coli which was higher than the other farm species in the study. In Iran virulence genes were detected in slaughter age goats [26] and also in US slaughter age goats [27].

Our study found a significantly higher prevalence of the $s t x 1$ and eaeA virulence genes in $E$. coli isolates from young nursing goat kids compared to their respective cohort of mothers grazing alongside them. Even for hly and stx 2 genes, although not significantly, the pattern was similar with higher proportions of isolates harboring the virulence genes in goat kids than in adults. Results from the goat kid cohort that was followed from 3 weeks 
of age to one year indicate a clear pattern where the prevalence of the virulence genes stx $1, h l y$ and stx 2 peaked at weaning and then decreased over time reaching significantly lower levels in the goats at one year of age. Furthermore, we report novel findings that indicated a significant increase and the highest number of isolates with stx 1 , hly and stx 2 virulence genes around the weaning. Our findings are similar to those reported by other groups who found a higher prevalence of shiga toxin producing E.coli in calves than adult cattle [36-40] and in piglets compared to sows in Poland [41]. In contrast, our findings differ from previous studies in goats that reported a higher prevalence of virulence genes in samples from adult and replacement animals than in young animals $[21,25,31]$. These differences in the findings could be due to a combination of factors that include the method of sampling (one time vs longitudinal study) [21, 31], geographical location (Europe vs US) $[21,25,31]$, age of animals included (4 weeks old goat kids [31] vs up to 13 weeks in in this study) and breed type (dairy goats vs meat goats in this study) [31] as well as management differences (artificial rearing vs nursing goat kids on pasture in this study) [25]. In one of these studies, differences in the age of first detection of Shiga toxin producing E.coli in young goat kids between the two farms that were followed over time was also reported [25] further indicating that several factors may affect the prevalence of virulence genes in goats. In cattle, a higher prevalence of shiga-toxin E.coli was reported in heifers than adult animals [42]. In the latter study, as animals increased in age after reaching maturity, the prevalence of virulence genes tended to decrease similar to findings in our study. The current study also found Stx1/Hly genes as the most common combination in all age groups which is similar to other studies in cattle that also found that E. coli isolates with Stx1/Hly virulence genes were common in all age groups [43]. While strains of E. coli having Stx 1 and Hly virulence genes alone are commonly found in healthy ruminants, the significance of these isolates in animals has not fully been explored. However, sero-groups O9, O22, O26, $\mathrm{O} 103$ and $\mathrm{O} 105$, that only possess these two virulence genes have been associated with human uraemic syndrome and have been isolated from healthy bovine species [44].

The enterocyte attaching and effacing (eaeA) gene protein (intimin) remains one of the important virulence factors that EPEC and STEC E.coli utilizes to cause intestinal pathology in both humans and animals $[45,46]$. In humans, EPEC strains cause diarrhea in young children and susceptibility is known to decline with age [7]. In a rabbit experimental model, the eaeA gene was required for colonization and pathology in the intestines by O157: H7 E.coli [47]. Shiga toxin producing E.coli that produce intimin are associated with hemorrhagic diarrhea and hemolytic uremic syndrome in humans although non-O157 STEC E.coli without the eaeA gene have also caused hemorrhagic uremic syndrome in outbreaks in the US and Australia [48, 49]. In the current study, E. coli with the intimin protein coding gene (eaeA) were most prevalent in healthy pre-weaned meat goats with the highest prevalence $(70 \%)$ being detected in healthy 3-week goat kids and declined as the kids grew older. Isolates with only eaeA gene (EPEC) were detected in $16 \%$ of pre-weaned goat kids. At one year of age, no eaeA gene was detected in any of the $E$. coli isolates. Similarly, other groups studying E.coli isolates from dairy cattle and dairy goats found that E.coli strains from calves [38] and goat kids [31] had a higher prevalence of eaeA gene than from adult dairy cattle and adult goats respectively. In a previous study, EPEC were suggested to play a role in diarrhea in goat kids and lambs [50]. Only a few isolates from diarrheic goats in this study possessed the eaeA gene. In agreement with our study, eaeA was detected in both healthy and diarrheic calves [51-53] with a higher prevalence in healthy calves compared to diarrheic calves [53]. Other previous studies in cattle, sheep and goats have reported similar prevalence of the eaeA gene in $E$. coli isolates from healthy and diarrheic animals. In a recent study characterizing virulence genes in $E$. coli isolates from diarrheic sheep, goats and calves, eaeA was not detected in isolates from sheep and goats [22] except from calves. Failure to detect high prevalence of the eaeA gene in isolates from diarrheic samples in this and previous studies may imply that eaeA gene protein is not required for $E$. coli colonization and disease pathology in the ruminant gut. Alternatively, it may be due to the fact that no direct $E$. coli diarrhea causal relationship was determined in these studies or age played a role in sheep and goats since EPEC are mostly associated in diarrhea in young animals. It is also possible that other microorganisms (viruses, parasites) may have been responsible for diarrhea in these animals as some studies also detected rotaviruses, coronaviruses, enterococcus and also Salmonella spp in the same animals [53]. In our present study, most of the diarrheic animals were detected in older kids (around 3 months) and were also parasitized by coccidia parasites and worms and detailed diagnostics to establish the exact cause of diarrhea was not pursued. Whether the eaeA positive $E$. coli isolates in healthy young goat kids detected in this study are potential pathogens in goats or humans remain to be evaluated. It may be that these isolates are potential pathogenic strains in very young animals that are kept in check by immune or bioactive molecules secreted in the gut by other beneficial gut microbes as has been reported for Bifidobacteria species in humans $[54,55]$ and/or produced from the 
mother's milk. In this case any stress that cause gut dysbiosis may therefore result in these isolates inducing disease in these animals.

Another important E. coli virulence gene evaluated was the Stx2 the product of which is the shiga toxin 2 . This factor is known to be of higher virulence than the shiga toxin 1 and play a significant role in disease pathology causation in human. Seven variants (a-g) of the stx 2 factor are known to exist with some being more virulent in humans than others (reviewed in [7]). The presence of Stx 2 virulence genes in E. coli in ruminants has been reported in many other studies involving dairy goats, cattle and sheep [31] but the significance of the gene has not been fully described. Some studies in cattle found over $50 \%$ of isolates from healthy animals carried the Stx2 genes [44] while other studies in healthy goats also found over $70 \%$ of isolates harboring the Stx 2 gene [56]. Furthermore, none of the previous studies has evaluated the temporal pattern of the $s t x 2$ gene in $E$. coli isolates from different age groups of ruminants. In this study we used two different stx 2 gene primers; one targeting the stx2 (EHEC) gene found in E.coli isolates associated with the hemorrhagic uremic syndrome (HUS) [57] and another set used in a previous ruminant study [53]. The prevalence of the EHEC type Stx2 virulence gene in the $E$. coli isolates from this cohort was relatively low compared to the other virulence genes evaluated. None of the E. coli isolates from goat kids prior to weaning, at 6 months, at one year or adult meat goats harbored this gene. Interestingly, the period around weaning was uniquely the only stage where this gene was detected in E. coli isolates from apparently healthy goat kids and isolates from diarrheic animals at weaning. No other study in the literature was found that had evaluated the temporal virulence gene detection in E. coli isolates from meat goats or other farm animals and focusing on weaning period specifically. On the other hand, using the primer set used in the ruminant study, this study detected $S t x 2$ gene in a large number of isolates from goat kids especially during weaning and also those from diarrheic animals compared to isolates from other age groups, a finding that has not been reported before. This finding calls for an understanding and further characterization of the stx 2 subtypes found in different farm animals, geographical regions and their clinical significance in these animals or in humans. Whether this pattern indicates a real significant role of the Stx2 in E. coli colonization of young diarrheic or stressed animals in meat goats remain to be further explored. In sheep, a higher number of shiga toxin E.coli (STEC) was reported in diarrheic lambs compared to healthy age matched lambs in the same study [6]. The exact reason for the pattern of higher detection of $s t x 2$ genes around weaning period is not clear. Whether the
Stx2 gene plays a role in virulence of $E$. coli isolates in ruminants has also not been fully understood. However, further characterization of the stx2 subtypes in goats need to be addressed to have clear understanding of the diversity and significance of these isolates. We postulate that the stress of weaning may have contributed to a reduced host immunity or altered gut homeostasis in these young goat kids. This may have made the gut environment favorable for proliferation of specific minor low copy numbers of $E$. coli strains that otherwise are unable to compete in normal healthy animals when stress is not a factor.

A number of E.coli sero-groups including the $\mathrm{O} 157$ and non $\mathrm{O} 157$ strains with and without the shiga toxin genes are of significance in both animal and public health (reviewed in [14]. Many of these serogroups have been found in the gut of healthy cattle and goats [27, 31, 44] underscoring the importance of determining serogroups of $E$. coli isolated from food animals including goats. Three sero-groups (O26, $\mathrm{O} 103$ and O146) of $E$. coli were detected in this study. Of note is that all the sero-groups strains detected in this study have been implicated either in diarrhea in ruminants (026) [58] or human infections $[14,17,18]$. These sero-groups were all interestingly detected around the weaning period in young goat kids. The finding again points to a possibility of stress playing a role in proliferation of important pathogenic E. coli strains. This is similar to findings reported in cattle $[29,30]$ for E.coli O157 strain. Furthermore in beef cattle, transitioning of beef calves from weaning to feedlot was also associated with an increased prevalence of important serogroups including 026, 0103, 045, 0121 and 0157 [59] again indicating a possible role of stress.

The phylogenetic diversity of $E$. coli isolates from goats is currently not fully understood. Furthermore, it is not known if any factors including age or stress play a role in diversity of the E. coli phylogenetic groups colonizing the gut of ruminants in general as this has not been reported anywhere in the literature. A few studies have reported the phylogenetic groups of E.coli from goats $[26,34,60-62]$ and other animals [63-66] in which either fewer isolates were evaluated and/or the isolates were all from adult animals or the age was not reported. This study characterized the phylogenetic distribution of $E$. coli isolates in different age groups using a cohort study that was evaluated over a one-year period. In this study, we detected the four main phylogenetic groups in goats with significant differences in the predominant phylogenetic groups based on the age and also weaning stress. Young meat goats less than six months were predominantly hosts to group D E. coli but these were mostly isolated during the weaning period. Goats six months and older were predominantly hosts to group 
B1. Our study findings are similar to $[26,34,60]$ who found a high prevalence of the B1 group in adult goats and a few isolates of A phylogenetic group. Although the prevalence in individual species was not mentioned, Derakhshandeh et al [64] also found a predominance of group D E.coli in ruminants that included goats. In adult lactating dairy cattle, group B1 was the predominant phylogenetic group detected followed by group A [67, 68]. Age also influenced the phylogenetic diversity of commensal E.coli in pigs where young piglets were mostly found to host phylogenetic group B1 and the sows group A [41]. This differs from our findings of group D being the predominant phylogenetic group in young meat goats and B1 in adults goats but may point out to the many factors including species, geographical location, and diet that are reported to influence phylogenetic diversity of $E$. coli isolates in the gut $[63,65,66$, 69]. Our study also detected group B2 E. coli isolates mostly in kids less than six months with the highest number of isolates being detected around the weaning period. In the previous studies evaluating E.coli isolates from goats $[26,34,60,61]$ only one reported a few isolates belonging to phylogenetic B2 [61]. E. coli isolates belonging to group A were very few in all age groups in this study. E. coli strains belonging to groups B2 and D are known to contain more virulence factors than groups $\mathrm{A}$ and $\mathrm{B} 1$ and also more commonly involved in extraintestinal infections especially group B2 [32]. The intestinal pathogenic strains are mainly found in groups A, B1 and D (reviewed in [34]. Thus in this study we detected E. coli strains belonging to phylogenetic groups that would be considered mostly normal commensals (A and B1) and also those that are potential pathogens although the prevalence depended on the age of the animals. To our knowledge this is the first study to evaluate and report on phylogenetic diversity of commensal $E$. coli in different age groups in small ruminants.

\section{Conclusion}

In this first of its kind study, we carried out a one-year longitudinal study using a cohort evaluating both the phylogenetic diversity of $E$. coli isolates from different age groups of pastured meat goats and also prevalence of virulence genes. We also evaluated the prevalence of select important sero-groups among the isolates detected from the different age groups. This study unraveled hitherto unreported unique patterns on phylogenetic diversity of $E$. coli, virulence gene and important serogroup prevalence patterns based on the age and growth phases in pastured meat goats. Additionally, we hereby report findings that some animal growth stages (weaning)/health status (diarrhea) probably due to their inherent stress inducing characteristics were associated with a higher prevalence of $E$. coli harboring important virulence genes and also isolates that belong to serogroups and phylogenetic groups that are important to both animal and human health. Thus more attention in reducing prevalence of these strains needs to focus on reducing stress in these animals and paying close attention to pre-weaning and weaning period. The significance of the $E$. coli virulence genes and phylogenetic groups found to differ based on age or during weaning in the ruminant gut or in public health may need further studies.

\section{Methods}

\section{Study animals and husbandry}

The study used adult and goat kids of Spanish and Myotonic breeds belonging to Virginia State University (VSU), USA, research flock. These animals are predominantly maintained on pasture except for the dry season when animals are supplemented with hay as needed. The goat kids used in the study were born on the farm. The original Myotonic and Spanish does and bucks were brought to the farm over ten years ago and are bred yearly, selected and replaced to maintain the best genetics. For the current study, the nursing does and any other adult goats were all between one and half to six years old.

\section{Animal sampling}

During 2017 kidding period, a group of twenty-five [25] newly born goat kids (pre-weaning kids) and nursing does (pre-weaning does) were randomly selected from the research flock and sampled to evaluate differences in diversity and virulence gene characteristics of $E$. coli isolates from growing goat kids and the respective nursing adult goats. Sampling started at the age of three weeks for the goat kids with subsequent samplings done monthly until the kids were three months old and ready for weaning. Around weaning, the kids were sampled at day of weaning (0DPW), one day after (1DPW), two days after (2DPW) and one week after weaning (7 DPW) (peri-weaning kids). Subsequently, the goat kids were sampled at six months (6 months) and at one year of age (yearling). The six months and one-year sampling group included the initial cohort of randomly selected goat kids (pre-weaning kids) and other littermates born at the same time, on the same research farm and maintained under the same management throughout the study. Inclusion of all littermates was done for increased statistical power. The adult goats were sampled during the pre-weaning period (pre-weaning does) and also when the goat kids were sampled at six months of age (adults). For phylogenetic characterization, additional 22 isolates from adults in the same farm from a previous study were also included. Additionally, fecal samples were collected from any goat kid that developed diarrhea during the 
study period. None of the animals were sacrificed during the study and at the end of the study they remained part of the research herd at Virginia State University. The study was approved by the Virginia State University Institutional Animal Care and Use committee under the Protocol (AACUC protocol 2017-01).

\section{Fecal sample processing}

Fecal samples were collected from individual goats per rectum using well lubricated gloves and immediately transported to the laboratory in ice for $E$. coli isolation. At each sampling points, kids with diarrhea were sampled separately and the fecal samples stored separately. The samples were processed the same day. Laboratory processing of the samples for E. coli isolation, confirmation and storage followed a previously described protocol [62]. E. coli ATCC 25922 was used as a positive control. Confirmed E. coli isolates were preserved in
$20 \%$ glycerol at $-20{ }^{\circ} \mathrm{C}$ or below pending processing for virulence genes, phylogenetic group determination and sero-groups.

\section{DNA extraction protocol}

DNA from each $E$. coli isolate was extracted from overnight culture in Luria broth grown at 37C. The DNA extraction protocol followed a simple boiling method [70] with a few modifications as described previously [62]. The concentration and purity of the extracted DNA was determined using a Nanodrop 2000c and samples stored at $-20 \mathrm{C}$ or below until further processing for determination of virulence genes, phylogenetic grouping and sero-groups.

\section{Detection of virulence genes and sero-groups}

Detection of virulence genes stx 1 , stx2, eaeA and hly in the E.coli isolates was done using $\mathrm{PCR}$ and primers

Table 3 Primers used in the study

\begin{tabular}{|c|c|c|c|c|}
\hline Fragment size (bp) & Target gene & Sequence $\left(5^{\prime}-3^{\prime}\right)$ & Primer & Ref \\
\hline \multirow[t]{2}{*}{338} & Stxl & TCTCAGTGGGCGTTCTTATG & Stx1-a & {$[57]$} \\
\hline & & TACCCCCTCAACTGCTAATA & Stx1-b & \\
\hline \multirow[t]{2}{*}{115} & Stx2(EHEC) & GCGGTTTATTTGCATTAGC & Stx2-a & [57] \\
\hline & & TCCCGTCAACCTTCACTGTA & Stx2-b & \\
\hline \multirow[t]{2}{*}{248} & eaeA & ATGCTTAGTGCTGGTTTAGG & EAEA-a & [57] \\
\hline & & GCCTTCATCATTTCGCTTTC & EAEA-b & \\
\hline \multirow[t]{2}{*}{569} & hlyA & AGCTGCAAGTGCGGGTCTG & HlyA-a & [57] \\
\hline & & TACGGGTTATGCCTGCAAGTTCAC & HlyA-b & \\
\hline \multirow[t]{2}{*}{152} & O26wZx & GCGCTGCAATTGCTTATGTA & Wzx-F & [72] \\
\hline & & TTTCCCCGCAATTTATTCAG & WzX-R & \\
\hline \multirow[t]{2}{*}{527} & O45wzx & CCGGGTTCGATTTGTGAAGGTTG & Wzx-F & {$[72]$} \\
\hline & & CACAACAGCCACTACTAGGCAGAA & WzX-R & \\
\hline \multirow[t]{2}{*}{321} & O103wzx & TTGGAGCGTTAACTGGACCT & Wzx-F & [72] \\
\hline & & GCTCCCGAGCACGTATAAG & WzX-R & \\
\hline \multirow[t]{2}{*}{925} & O126wzx & TTAGCTCTCGTAGAGGCTGGTGTT & WzX-F & [72] \\
\hline & & ATGTCATTCCTGGGACGCGAATGT & Wzx-R & \\
\hline \multirow[t]{2}{*}{640} & O146wzx & AGGGTGACCATCAACACACTTGGA & $w Z X-F$ & {$[72]$} \\
\hline & & AGTTCAATACTGTCGCAGCTCCTC & $w Z X-R$ & \\
\hline \multirow[t]{2}{*}{118} & Stx2 & GTGCCTGTTACTGGGTTITCTTC & Stx2F & [53] \\
\hline & & AGGGGTCGATATCTCTGTCC & St $\times 2 R$ & \\
\hline \multirow[t]{2}{*}{211} & yjaA & TGAAGTGTCAGGAGACGCTG & YjaA.1 & [32] \\
\hline & & ATGGAGAATGCGTTCCTCAAC & YjaA.2 & \\
\hline \multirow[t]{2}{*}{152} & tspE4.C2 & GAGTAATGTCGGGGCATTCA & TspE4C2.1 & [32] \\
\hline & & CGCGCCAACAAAGTATTACG & TspE4C2.2 & \\
\hline \multirow[t]{2}{*}{279} & chuA & GACGAACCA ACGGTCAGGAT & ChuA.1 & [32] \\
\hline & & TGCCGCCAGTACC AAAGACA & ChuA.2 & \\
\hline \multirow[t]{2}{*}{401} & E. coli $16 \mathrm{~s}$ & CCCCCTGGACGAAGACTGAC & EC16S-a & {$[57]$} \\
\hline & & ACCGCTGGCAACAAAGGATA & EC16S-b & \\
\hline
\end{tabular}


Table 4 Statistical results of comparisons of proportions of virulence genes and phylogenetic groups of isolates analyzed using MedCalc Software

\begin{tabular}{|c|c|c|}
\hline Comparison groups & Chi square value & $\boldsymbol{P}$ value \\
\hline Pre-weaned kids vs nursing does st $x 1$ & 13.803 & $P=0.0002$ \\
\hline Pre-weaned kids vs nursing does st $\times 2$ & 3.160 & $P=0.0755$ \\
\hline Pre-weaned kids vs nursing does eaeA & 18.394 & $P<0.0001$ \\
\hline Pre-weaned kids vs nursing does hly & 2.813 & $P=0.0935$ \\
\hline Kids ODPW vs kids 1DPW Stx1 & 14.5 & $P=0.0001$ \\
\hline Kids ODPW vs kids 2DPW Stx1 & 11.5 & $P=0.0007$ \\
\hline Kids ODPW vs kids 7DPW Stx1 & 6.8 & $P=0.009$ \\
\hline Kids ODPW vs kids 1DPW hly & 15.2 & $P=0.0001$ \\
\hline Kids ODPW vs kids 2DPW hly & 24.5 & $P<0.0001$ \\
\hline Kids ODPW vs kids 7DPW hly & 21.0 & $P<0.0001$ \\
\hline Preweaned and periweaning kids vs all adults hly & 28.1 & $P<0.0001$ \\
\hline Preweaned and periweaning kids vs all adults STEC & 41.4 & $P<0.0001$ \\
\hline Preweaned and periweaning kids vs all adults all virulence genes & 25.4 & $P<0.0001$ \\
\hline Preweaned and periweaning kids vs all adults 2 or more virulence genes & 26.48 & $P<0.0001$ \\
\hline Group D phylogenetic group (diarrhea (kids) vs healthy littermates) & 3.709 & $P=0.0541$ \\
\hline Group D phylogenetic group (goat kids vs adults) & 27.480 & $P<0.0001$ \\
\hline Group D phylogenetic group (pre-weaning kid vs weaning period) & 4.727 & $P=0.0297$ \\
\hline Group B phylogenetic group (adults vs goat kids) & 20.860 & $P<0.0001$ \\
\hline
\end{tabular}

previously described in two studies [57, 71] using conventional PCR (stx1, stx2, eaeA and $h l y)$ and also SYBR green real time detection protocol (Stx1,stx2 and eaeA (Table 3). One Stx2 primer targeted the E.coli 0157: H7 stx2 gene (enterohemorrhagic Escherichia coli (EHEC) [57] while the other primer targeted a st $x 2$ gene previously detected in ruminants $(s t x 2)[53,71]$. E. coli ATCC 35150 was used as a positive control strains for the virulence genes while water was used as negative control. The amplified products were visualized under UV light in a gel imager after separation in $2 \%$ ethidium bromide containing agarose gel. For SYBR green real time detection a cycle threshold of 30 and melting curve analysis was used to confirm the presence of the genes.

Similarly, O sero-group primers specific for the conserved part of the $\mathrm{O}$ antigen gene ( $w z x$ gene) [72] (Table 3) were used for screening for the presence of select important non-O157 sero-groups (O146, O126, O45, O103, and O26) using conventional PCR followed by visualization under UV light in $2 \%$ gel. These sero-groups were chosen based on their reported association with either diarrhea in food animals and/or food safety in human and also recent detection in goats at slaughter.

\section{Characterization of phylogenetic groups}

Each confirmed E.coli isolate was subjected to a multiplex PCR of the genes chuA, yjaA and DNA fragment
TspE4.C2 following the previously described protocol [32] and the primers (Table 3) to determine the phylogenetic grouping. The amplified products were electrophoresed in a $2 \%$ ethidium bromide agarose gel and visualized under UV light in a gel imager. The isolates were grouped in to either A, B1, B2 or D groups based on the presence or absence of the three genes as previously described [32].

\section{Statistical analysis}

The proportions of isolates with evaluated traits (virulence genes, phylogenetic groups) were determined for all age groups. Each individual isolate was considered the unit of analysis. The differences in proportion of isolates with each trait among age groups were tested using the MedCalc N-1 Chi-squared Comparison of proportions calculator 2020 [73]. Statistical comparisons were considered significant at $P<0.05$ (Table 4).

\section{Supplementary information}

Supplementary information accompanies this paper at https://doi.org/10. 1186/s12917-020-02479-0.

Additional file 1 Table 1. Virulence gene profiles of isolates harboring virulence genes and their corresponding phylogenetic groups.

Additional file 2 Table 2. Virulence profiles and phylogenetic groups of sero-groups detected in the study. 


\section{Abbreviations}

Stx: Shiga toxin; eaeA: Effacing and attaching; hly: Hemolysin; $E$ coli: Escherichia coli; EHEC: Enterohemorrhagic Escherichia coli; STEC: Shiga toxin producing Escherichia coli; DPW: Days post weaning;

DNA: Deoxyribonucleic acid; PCR: Polymerase chain reaction; US: United States; wzx: The $\mathrm{O}$ antigen processing proteins, the Wzx ( $\mathrm{O}$ antigen flippase)

\section{Acknowledgments}

The authors wish to acknowledge the support given by Virginia State University herd manager Amanda Miller and her team for the assistance in animal management and handling. We also acknowledge the laboratory help offered by Ms. Zhenping Wang.

\section{Authors' contributions}

EN conceptualized the study including methodology and funding acquisition. EN, AA carried out the investigation including formal analysis and data analysis. EN, CK, PK, and DO supervised the investigation. EN and AA drafted manuscript. EN, AA, CK, PK and DO reviewed and edited the manuscript. The authors read and approved the final manuscript.

\section{Funding}

All the work was supported financially by a USDA NIFA Evans Allen (Accession \# 1013065) project through Agricultural Research Station (ARS), Virginia State University, USA. The corresponding author is employed as an Animal Health Researcher at the ARS. The funding agency had no role in the conception, designing, data collection or interpretation of the data reported in the study.

\section{Availability of data and materials}

We have attempted to include all data generated and used to draw conclusions during the study in the manuscript but it is also available from the corresponding author upon request.

\section{Ethics approval and consent to participate}

The study was approved by Virginia State University Institutional Animal Care and Use committee and all animal handling protocols were carried out according to an approved AACUC VSU protocol 2017-01.

\section{Consent for publication}

Not applicable.

\section{Competing interests}

The authors have no competing interests.

\section{Author details}

${ }^{1}$ Agricultural Research Station, Virginia State University, Petersburg, VA 23806, USA. ${ }^{2}$ Department of Biology, Virginia State University, Petersburg, VA 23806, USA. ${ }^{3}$ College of Agriculture, Virginia Cooperative Extension, Virginia State University, Petersburg, VA 23806, USA.

\section{Received: 24 February 2020 Accepted: 15 July 2020}

Published online: 30 July 2020

\section{References}

1. Gillespie J, Nyaupane N, Dunn B, McMillin K. Why do farmers decide to produce meat goats? Evidence from the United States. Agric Hum Values. 2016;33(4):911-27.

2. Kritas S. Prevention of scours in neonatal kids after oral administration of an organic acid solution. J Veterinary Med Ser A. 2002;49(1):23-6.

3. Kritas S, Burriel A, Tzivara A, Govaris A, Kyriakis S, Karatzias H, et al. Prevention of scours in neonatal kids after modification of management and experimental vaccination against Escherichia coli. Small Rumin Res. 2003;50(1-2):51-6.

4. Kaper JB, Nataro JP, Mobley HLT. Pathogenic Escherichia coli. Nat Rev Microbiol. 2004;2(2):123-40

5. Foster D, Smith GW. Pathophysiology of diarrhea in calves. Vet Clin N Am Food Anim Pract. 2009;25(1):13-36.

6. Bhat M, Nishikawa Y, Wani S. Prevalence and virulence gene profiles of Shiga toxin-producing Escherichia coli and enteropathogenic Escherichia coli from diarrhoeic and healthy lambs in India. Small Rumin Res. 2008; 75(1):65-70
7. Croxen MA, Law RJ, Scholz R, Keeney KM, Wlodarska M, Finlay BB. Recent advances in understanding enteric pathogenic Escherichia coli. Clin Microbiol Rev. 2013;26(4):822-80.

8. Aidar-Ugrinovich L, Blanco J, Blanco M, Blanco J, Leomil L, Dahbi G, et al. Serotypes, virulence genes, and intimin types of Shiga toxin-producing Escherichia coli (STEC) and enteropathogenic E. coli (EPEC) isolated from calves in São Paulo, Brazil. Int J Food Microbiol. 2007;115(3):297-306.

9. Law D. Virulence factors of Escherichia coli 0157 and other Shiga toxinproducing E. coli. J Appl Microbiol. 2000;88(5):729-45.

10. Sandvig K. Shiga toxins. Toxicon. 2001;39(11):1629-35.

11. Leomil L, Aidar-Ugrinovich L, Guth B, Irino K, Vettorato M, Onuma D, et al. Frequency of Shiga toxin-producing Escherichia coli (STEC) isolates among diarrheic and non-diarrheic calves in Brazil. Vet Microbiol. 2003;97(1-2):103-9.

12. Brooks JT, Sowers EG, Wells JG, Greene KD, Griffin PM, Hoekstra RM, et al. Non-O157 Shiga toxin-producing Escherichia coli infections in the United States, 1983-2002. J Infect Dis. 2005;192(8):1422-9.

13. Coombes BK, Wickham ME, Mascarenhas M, Gruenheid S, Finlay BB, Karmali MA. Molecular analysis as an aid to assess the public health risk of non-0157 Shiga toxin-producing Escherichia coli strains. Appl Environ Microbiol. 2008; 74(7):2153-60.

14. Hughes JM, Wilson ME, Johnson KE, Thorpe CM, Sears CL. The emerging clinical importance of non-0157 Shiga toxin-producing Escherichia coli. Clin Infect Dis. 2006;43(12):1587-95.

15. Melton-Celsa AR. Shiga toxin (Stx) classification, structure, and function. In: Vanessa S Carolyn JH, editors. Enterohemorrhagic Escherichia coli and other Shiga toxin-producing Escherichia. coli. USA. Copyright @American Society of Microbiology; 2015. https://doi.org/10.1128/9781555818791.ch3.

16. Bettelheim KA. The non-O157 Shiga-toxigenic (verocytotoxigenic) Escherichia coli; under-rated pathogens. Crit Rev Microbiol. 2007;33(1):67-87.

17. Luna-Gierke R, Griffin P, Gould L, Herman K, Bopp C, Strockbine N, et al. Outbreaks of non-0157 Shiga toxin-producing Escherichia coli infection: USA. Epidemiol Infect. 2014;142(11):2270-80.

18. Mathusa EC, Chen Y, Enache E, Hontz L. Non-O157 Shiga toxin-producing Escherichia coli in foods. J Food Prot. 2010;73(9):1721-36.

19. Brown JA, Hite DS, Gillim-Ross LA, Maguire HF, Bennett JK, Patterson JJ, et al. Outbreak of Shiga toxin-producing Escherichia coli serotype O26: H11 infection at a child care center in Colorado. Pediatr Infect Dis J. 2012;31(4):379-83.

20. Hazards EPoB. Scientific opinion on the public health hazards to be covered by inspection of meat from sheep and goats. EFSA J. 2013;11(6):3265.

21. Orden J, Ruiz-Santa-Quiteria J, Blanco M, Blanco J, Mora A, Cid D, et al. Prevalence and characterization of Vero cytotoxin-producing Escherichia coli isolated from diarrhoeic and healthy sheep and goats. Epidemiol Infect. 2003;130(2):313-21.

22. Osman K, Mustafa A, Elhariri M, Abdelhamed G. The distribution of Escherichia coli serovars, virulence genes, gene association and combinations and virulence genes encoding serotypes in pathogenic E. coli recovered from diarrhoeic calves, sheep and goat. Transbound Emerg Dis. 2013;60(1):69-78.

23. Zschöck M, Hamann H, Kloppert B, Wolter W. Shiga-toxin-producing Escherichia coli in faeces of healthy dairy cows, sheep and goats: prevalence and virulence properties. Lett Appl Microbiol. 2000;31(3):203-8.

24. Rdl F, García S, Orden JA, Ruiz-Santa-Quiteria JA, Díez R, Cid D. Prevalence and characteristics of attaching and effacing strains of Escherichia coli isolated from diarrheic and healthy sheep and goats. J Am Vet Med Assoc. 2002;63(2):262-6.

25. Orden J, Cortés C, Horcajo P, De la Fuente R, Blanco J, Mora A, et al. A longitudinal study of verotoxin-producing Escherichia coli in two dairy goat herds. Vet Microbiol. 2008;132(3-4):428-34.

26. Jajarmi M, Badouei MA, Fooladi AAl, Ghanbarpour R, Ahmadi A. Pathogenic potential of Shiga toxin-producing Escherichia coli strains of caprine origin: virulence genes, Shiga toxin subtypes, phylogenetic background and clonal relatedness. BMC Vet Res. 2018;14(1):97.

27. Jacob M, Foster D, Rogers A, Balcomb C, Shi X, Nagaraja T. Evidence of non0157 Shiga toxin-producing Escherichia coli in the feces of meat goats at a US slaughter plant. J Food Prot. 2013;76(9):1626-9.

28. Fernández D, Rodriguez E, Arroyo GH, Padola NL, Parma AE. Seasonal variation of Shiga toxin-encoding genes (stx) and detection of E. coli 0157 in dairy cattle from Argentina. J Appl Microbiol. 2009;106(4):1260-7.

29. Dewell G, Simpson C, Dewell R, Hyatt D, Belk K, Scanga J, et al. Impact of transportation and lairage on hide contamination with Escherichia coli 0157 in finished beef cattle. J Food Prot. 2008:71(6):1114-8. 
30. Bach S, McAllister T, Mears G, Schwartzkopf-Genswein K. Long-haul transport and lack of preconditioning increases fecal shedding of Escherichia coli and Escherichia coli 0157: H7 by calves. J Food Prot. 2004;67(4):672-8.

31. Cortés C, De la Fuente R, Blanco J, Blanco M, Blanco J, Dhabi G, et al. Serotypes, virulence genes and intimin types of verotoxin-producing Escherichia coli and enteropathogenic E. coli isolated from healthy dairy goats in Spain. Vet Microbiol. 2005;110(1-2):67-76.

32. Clermont $\mathrm{O}$, Bonacorsi S, Bingen E. Rapid and simple determination of theEscherichia coli phylogenetic group. Appl Environ Microbiol. 2000;66(10): 4555-8.

33. Herzer PJ, Inouye S, Inouye M, Whittam TS. Phylogenetic distribution of branched RNA-linked multicopy single-stranded DNA among natural isolates of Escherichia coli. J Bacteriol. 1990;172(11):6175-81.

34. Carlos C, Pires MM, Stoppe NC, Hachich EM, Sato MI, Gomes TA, et al. Escherichia coli phylogenetic group determination and its application in the identification of the major animal source of fecal contamination. BMC Microbiol. 2010;10(1):161

35. Álvarez-Suárez M-E, Otero A, García-López M-L, Dahbi G, Blanco M, Mora A, et al. Genetic characterization of Shiga toxin-producing Escherichia coli (STEC) and atypical enteropathogenic Escherichia coli (EPEC) isolates from goat's milk and goat farm environment. Int J Food Microbiol. 2016;236:148-54.

36. Wells J, Shipman L, Greene K, Sowers E, Green J, Cameron D, et al. Isolation of Escherichia coli serotype 0157: H7 and other Shiga-like-toxin-producing E. coli from dairy cattle. J Clin Microbiol. 1991;29(5):985-9.

37. Wilson J, McEwen S, Clarke R, Leslie K, Wilson R, Waltner-Toews D, et al. Distribution and characteristics of verocytotoxigenic Escherichia coli isolated from Ontario dairy cattle. Epidemiol Infect. 1992;108(3):423-39.

38. Blanco M, Blanco JE, Blanco J, Mora A, Prado C, Alonso MP, et al. Distribution and characterization of faecal verotoxin-producing Escherichia coli (VTEC) isolated from healthy cattle. Vet Microbiol. 1997;54(3-4):309-19.

39. Blanco M, Blanco J, Blanco J, Gonzalez E, Mora A, Prado C, et al. Prevalence and characteristics of Escherichia coil serotype 0157: H7 and other verotoxinproducing E. coli in healthy cattle. Epidemiol Infect. 1996;117(2):251-7.

40. Mir RA, Weppelmann TA, Elzo M, Ahn S, Driver JD, Jeong KC. Colonization of beef cattle by Shiga toxin-producing Escherichia coli during the first year of life: a cohort study. PLoS One. 2016. https://doi.org/10.1371/journal.pone. 0148518.

41. Bok E, Mazurek J, Pusz P, Stosik M, Baldy-Chudzik K. Age as a factor influencing diversity of commensal E. coli microflora in pigs. Pol J Microbiol. 2013;62(2):165-71.

42. Mir RA, Weppelmann TA, Kang M, Bliss TM, DiLorenzo N, Lamb GC, et al. Association between animal age and the prevalence of Shiga toxinproducing Escherichia coli in a cohort of beef cattle. Vet Microbiol. 2015; 175(2-4):325-31.

43. Döpfer D, Geue L, Schares S, Mintel B, Hoffmann B, Fischer E. Dynamics of Shiga-toxin producing Escherichia coli (STEC) and their virulence factors in cattle. Prev Vet Med. 2012;103(1):22-30.

44. Blanco M, Blanco J, Mora A, Dahbi G, Alonso M, González E, et al. Serotypes, virulence genes, and intimin types of Shiga toxin (verotoxin)-producing Escherichia coli isolates from cattle in Spain and identification of a new intimin variant gene (eae-६). J Clin Microbiol. 2004;42(2):645-51.

45. McDaniel TK, Jarvis KG, Donnenberg MS, Kaper JB. A genetic locus of enterocyte effacement conserved among diverse enterobacterial pathogens. Proc Natl Acad Sci. 1995;92(5):1664-8.

46. Nataro JP, Kaper JB. Diarrheagenic escherichia coli. Clin Microbiol Rev. 1998; 11(1):142-201.

47. Ritchie JM, Thorpe CM, Rogers AB, Waldor MK. Critical roles for stx2, eae, and tir in enterohemorrhagic Escherichia coli-induced diarrhea and intestinal inflammation in infant rabbits. Infect Immun. 2003;71(12):7129-39.

48. Paton AW, Paton JC. Direct detection and characterization of Shiga toxigenic Escherichia coli by multiplex PCR for stx1, st×2, eae, ehxA, and saa. J Clin Microbiol. 2002;40(1):271-4.

49. Paton AW, Woodrow MC, Doyle RM, Lanser JA, Paton JC. Molecular characterization of a Shiga ToxigenicEscherichia coli O113: H21 strain lacking eaeResponsible for a cluster of cases of hemolytic-uremic syndrome. J Clin Microbiol. 1999;37(10):3357-61.

50. Turkyilmaz S, Eskiizmirliler S, Tunaligil S, Bozdogan B. Identification, characterization and molecular epidemiology of Escherichia coli isolated from lamb and goat kids with diarrhoea. Acta Vet Brno. 2013;82(4):357-62.

51. Badouei MA, Salehi TZ, Khorasgani MR, Tadjbakhsh H, Brujeni GN, Nadalian M. Virulence gene profiles and intimin subtypes of Shiga toxin-producing
Escherichia coli isolated from healthy and diarrhoeic calves. Vet Rec. 2010; 167(22):858.

52. Nguyen TD, Vo TT, Vu-Khac H. Virulence factors in Escherichia coli isolated from calves with diarrhea in Vietnam. J Vet Sci. 2011;12(2):159-64.

53. Ok M, Güler L, Turgut K, Ok Ü, Şen I, Gündüz I, et al. The studies on the aetiology of diarrhoea in neonatal calves and determination of virulence gene markers of Escherichia coli strains by multiplex PCR. Zoonoses Public Health. 2009;56(2):94-101.

54. Ibrahim SA, Bezkorovainy A. Inhibition of Escherichia coli by bifidobacteria. J Food Prot. 1993;56(8):713-5.

55. Gagnon M, Kheadr EE, Le Blay G, Fliss I. In vitro inhibition of Escherichia coli 0157: H7 by bifidobacterial strains of human origin. Int J Food Microbiol. 2004;92(1):69-78.

56. Beutin L, Geier D, Steinrück H, Zimmermann S, Scheutz F. Prevalence and some properties of verotoxin (Shiga-like toxin)-producing Escherichia coli in seven different species of healthy domestic animals. J Clin Microbiol. 1993;31(9):2483-8.

57. Wang G, Clark CG, Rodgers FG. Detection in Escherichia coli of the genes encoding the major virulence factors, the genes defining the 0157: H7 serotype, and components of the type 2 Shiga toxin family by multiplex PCR. J Clin Microbiol. 2002;40(10):3613-9.

58. Sandhu K, Clarke R, McFadden K, Brouwer A, Louie M, Wilson J, et al. Prevalence of the eaeA gene in verotoxigenic Escherichia coli strains from dairy cattle in Southwest Ontario. Epidemiol Infect. 1996;116(1):1-7.

59. Hallewell J, Reuter T, Stanford K, Topp E, Alexander TW. Monitoring seven potentially pathogenic Escherichia coli serogroups in a closed herd of beef cattle from weaning to finishing phases. Foodborne Pathog Dis. 2016;13(12):661-7.

60. Taghadosi R, Shakibaie MR, Alizade H, Hosseini-Nave H, Askari A, Ghanbarpour R. Serogroups, subtypes and virulence factors of Shiga toxinproducing Escherichia coli isolated from human, calves and goats in Kerman, Iran. Gastroenterol Hepatol Bed to Bench. 2018;11(1):60.

61. Jajarmi M, Ghanbarpour R, Sharifi H, Golchin M. Distribution pattern of EcoR phylogenetic groups among Shiga toxin-producing and enteropathogenic Escherichia coli isolated from healthy goats. Int J Enteric Pathog. 2015;3(3):1-27971.

62. Ndegwa E, Almehmadi H, Chyer K, Kaseloo P, Ako AA. Longitudinal shedding patterns and characterization of antibiotic Resistant E. coli in pastured goats using a cohort study. Antibiotics. 2019;8(3):136.

63. Morcatti CF, Diniz SdA, Silva MX, Mussi JMS, Barbosa SM, Lage AP, et al. Phylogenetic group determination of Escherichia coli isolated from animal samples. The Scient World J. 2015;2015:258424.

64. Derakhshandeh A, Firouzi R, Naziri Z. Phylogenetic group determination of faecal Escherichia coli and comparative analysis among different hosts. Iranian J Veterinary Res. 2014;15(1):13-7.

65. Escobar-Páramo P, Le Menac'h A, Le Gall T, Amorin C, Gouriou S, Picard B, et al. Identification of forces shaping the commensal Escherichia coli genetic structure by comparing animal and human isolates. Environ Microbiol. 2006;8(11):1975-84.

66. Gordon DM, Cowling A. The distribution and genetic structure of Escherichia coli in Australian vertebrates: host and geographic effects. Microbiology. 2003;149(12):3575-86.

67. Houser BA, Donaldson SC, Padte R, Sawant AA, DebRoy C, Jayarao BM. Assessment of phenotypic and genotypic diversity of Escherichia coli shed by healthy lactating dairy cattle. Foodborne Pathog Dis. 2008;5(1):41-51.

68. Son I, Van Kessel JAS, Karns JS. Genotypic diversity of Escherichia coli in a dairy farm. Foodborne Pathog Dis. 2009;6(7):837-47.

69. Escobar-Páramo P, Grenet K, Le Menac'h A, Rode L, Salgado E, Amorin C, et al. Large-scale population structure of human commensal Escherichia coli isolates. Appl Environ Microbiol. 2004;70(9):5698-700.

70. Tobias J, Vutukuru S-R. Simple and rapid multiplex PCR for identification of the main human diarrheagenic Escherichia coli. Microbiol Res. 2012;167(9):564-70.

71. Franck SM, Bosworth BT, Moon HW. Multiplex PCR for enterotoxigenic, attaching and effacing, and Shiga toxin-producing Escherichia coli strains from calves. J Clin Microbiol. 1998;36(6):1795-7.

72. DebRoy C, Roberts E, Fratamico PM. Detection of $O$ antigens in Escherichia coli. Anim Health Res Rev. 2011;12(2):169-85.

73. MEDCALC ${ }^{\oplus}$. MedCalc comparison of proportions calculator $2020 ; 2020$. Available from: https://www.medcalc.org/calc/comparison_of_proportions.php.

\section{Publisher's Note}

Springer Nature remains neutral with regard to jurisdictional claims in published maps and institutional affiliations. 